\title{
BMJ Open Lack of an association or an inverse association between low-density- lipoprotein cholesterol and mortality in the elderly: a systematic review
}

Uffe Ravnskov, ${ }^{1}$ David M Diamond, ${ }^{2}$ Rokura Hama, ${ }^{3}$ Tomohito Hamazaki, ${ }^{4}$ Björn Hammarskjöld, ${ }^{5}$ Niamh Hynes, ${ }^{6}$ Malcolm Kendrick, ${ }^{7}$ Peter H Langsjoen, ${ }^{8}$ Aseem Malhotra, ${ }^{9}$ Luca Mascitelli, ${ }^{10}$ Kilmer S McCully, ${ }^{11}$ Yoichi Ogushi, ${ }^{12}$ Harumi Okuyama, ${ }^{13}$ Paul J Rosch, ${ }^{14}$ Tore Schersten, ${ }^{15}$ Sherif Sultan, ${ }^{6}$ Ralf Sundberg ${ }^{16}$

To cite: Ravnskov U, Diamond DM, Hama R, et al. Lack of an association or an inverse association between low-density-lipoprotein cholesterol and mortality in the elderly: a systematic review. BMJ Open 2016;6: e010401. doi:10.1136/ bmjopen-2015-010401

- Prepublication history for this paper is available online. To view these files please visit the journal online (http://dx.doi.org/10.1136/ bmjopen-2015-010401).

Received 5 November 2015 Revised 21 April 2016 Accepted 11 May 2016

CrossMark

For numbered affiliations see end of article.

Correspondence to Dr Uffe Ravnskov; ravnskov@tele2.se

\section{ABSTRACT}

Objective: It is well known that total cholesterol becomes less of a risk factor or not at all for all-cause and cardiovascular (CV) mortality with increasing age, but as little is known as to whether low-density lipoprotein cholesterol (LDL-C), one component of total cholesterol, is associated with mortality in the elderly, we decided to investigate this issue.

Setting, participants and outcome measures: We sought PubMed for cohort studies, where LDL-C had been investigated as a risk factor for all-cause and/ or CV mortality in individuals $\geq 60$ years from the general population.

Results: We identified 19 cohort studies including 30 cohorts with a total of 68094 elderly people, where all-cause mortality was recorded in 28 cohorts and CV mortality in 9 cohorts. Inverse association between allcause mortality and LDL-C was seen in 16 cohorts (in 14 with statistical significance) representing $92 \%$ of the number of participants, where this association was recorded. In the rest, no association was found. In two cohorts, CV mortality was highest in the lowest LDL-C quartile and with statistical significance; in seven cohorts, no association was found.

Conclusions: High LDL-C is inversely associated with mortality in most people over 60 years. This finding is inconsistent with the cholesterol hypothesis (ie, that cholesterol, particularly LDL-C, is inherently atherogenic). Since elderly people with high LDL-C live as long or longer than those with low LDL-C, our analysis provides reason to question the validity of the cholesterol hypothesis. Moreover, our study provides the rationale for a re-evaluation of guidelines recommending pharmacological reduction of LDL-C in the elderly as a component of cardiovascular disease prevention strategies.

\section{INTRODUCTION}

\section{Rationale}

For decades, the mainstream view has been that an elevated level of total cholesterol
Strengths and limitations of this study

- This is the first systematic review of cohort studies where low-density lipoprotein cholesterol (LDL-C) has been analysed as a risk factor for all-cause and/or cardiovascular mortality in elderly people.

- Lack of an association or an inverse association between LDL-C and mortality was present in all studies.

- We may not have included studies where an evaluation of LDL-C as a risk factor for mortality was performed but where it was not mentioned in the title or in the abstract.

- We may have overlooked relevant studies because we have only searched PubMed.

- Minor errors may be present because some of the authors may not have adjusted LDL-C by appropriate risk factors.

- Some of the participants with high LDL-C may have started statin treatment during the observation period and, in this way, may have added a longer life to the group with high LDL-C and some of them may have started with a diet able to influence the risk of mortality.

- We may have overlooked a small number of relevant studies because we only searched papers in English.

(TC) is a primary cause of atherosclerosis and cardiovascular disease (CVD). There are several contradictions to this view, however. No study of unselected people has found an association between TC and degree of atherosclerosis. ${ }^{1}$ Moreover, in most of the Japanese epidemiological studies, high TC is not a risk factor for stroke, and further, there is an inverse association between TC and allcause mortality, irrespective of age and sex. ${ }^{2}$

In a recent meta-analysis performed by the Prospective Studies Collaboration, there was 
an association between TC and CV mortality in all ages and in both sexes. ${ }^{3}$ However, even in this analysis, the risk decreased with increasing age and became minimal after the age of 80 years. Since atherosclerosis and CVD are mainly diseases of the elderly, the cholesterol hypothesis predicts that the association between CV mortality and TC should be at least as strong in the elderly as in young people. There may be a confounding influence in these studies, however, because TC includes high-density lipoprotein cholestrol (HDL-C), and multiple studies have shown that a high level of HDL-C is associated with a lower risk of CVD.

\section{Objectives}

We examined the literature assessing low-density lipoprotein cholesterol (LDL-C) as a risk factor for mortality in elderly people. Since the definition of CVD varies considerably in the scientific literature, we have chosen to focus on the association between LDL-C and all-cause and CVD mortality, because mortality has the least risk of bias among all outcome measures. If Goldstein and Brown's recent statement that LDL-C is 'the essential causative agent' of $\mathrm{CVD}^{4}$ is correct, then we should find that LDL-C is a strong risk factor for mortality in elderly people.

\section{METHODS}

\section{Search strategy}

UR and RS searched PubMed independently from initial to 17 December 2015. The following keywords were used: 'lipoprotein AND (old OR elderly) AND mortality NOT animal NOT trial'. We also retrieved the references in the publications so as not to miss any relevant studies. The search was limited to studies in English.

\section{Inclusion and exclusion criteria}

All included studies should meet the following criteria: the study should be a cohort study of people aged 60 years or older selected randomly from the general population, or a study where the authors had found no significant differences between the participants and the source population's demographic characteristics. The studies should include an initial assessment of LDL-C levels, the length of the observation time and information about all-cause and/or cardiovascular mortality at the end of follow-up. The studies should also include information about the association between LDL-C and all-cause and/or CVD mortality. We excluded studies that did not represent the general population (eg, case-control studies; case reports; studies that included patients only); studies where data about elderly people were not given separately, and studies without multivariate correction for the association between LDL-C and all-cause and/or CV mortality. We accepted studies where the authors had excluded patients with serious diseases or individuals who had died during the first year.
Study selection, data items and extraction

Studies where the title or abstract indicated that they might include LDL-C data of elderly people, were read in full, and the relevant data were extracted by at least three of the authors, for example, year of publication, total number of participants, sex, length of observation time, exclusion criteria, LDL-C measured at the start and the association between initial LDL-C and risk of allcause and/or CV mortality at follow-up. When more than one adjusted HR was reported, the HR with the most fully adjusted model was selected.

\section{Quality assessment}

The design of the study satisfies almost all points of reliability and validity according to the Newcastle Ottawa Scale as regards selection, comparability and exposure. ${ }^{5}$ Thus, all studies represented elderly people only; ascertainness of exposure (eg, measurement of LDL-C) was present in all studies, and outcome was unknown at the start. It can be questioned if all of the studies represented the general population because, as shown below, in some of them various types of disease groups were excluded.

\section{RESULTS}

\section{Study selection}

Our search gave 2894 hits. We excluded 160 studies, which were not in English, and 2452 studies because, judged from the abstract, it was obvious that they were irrelevant.

The rest of the papers were read in full; 263 of these studies were excluded for the following reasons: (1) the participants did not represent the general population; (2) LDL-C was not measured at the start; (3) follow-up information was not given for the elderly separately; or (4) no information was present about mortality during the observation period (figure 1). One of the studies ${ }^{6}$ was excluded because it included the same individuals as in a previous study. ${ }^{7}$

\section{Study characteristics}

The remaining 19 studies including 30 cohorts with a total of 68094 participants met the inclusion criteria (figure 1). All-cause mortality was recorded in 28 cohorts. In 16 of these cohorts (representing 92\% of the individuals), the association was inverse and with statistical significance in 14; in 1 of the cohorts, the association was mirror-J-formed with the lowest risk in the highest quartile; in the rest of the papers, no association was found. CV mortality was recorded in nine cohorts; in one of them, the association was almost U-shaped with the lowest risk in the highest quartile (curvilinear fit: $p=0.001)$; in one of them, the association was mirror-J-formed and also with the lowest risk in the highest quartile (curvilinear fit: $\mathrm{p}=0.03$ ); in the other seven cohorts, no association was found (table 1). 
Figure 1 Flow Chart. CV, cardiovascular; LDL-C, low-density lipoprotein cholesterol.

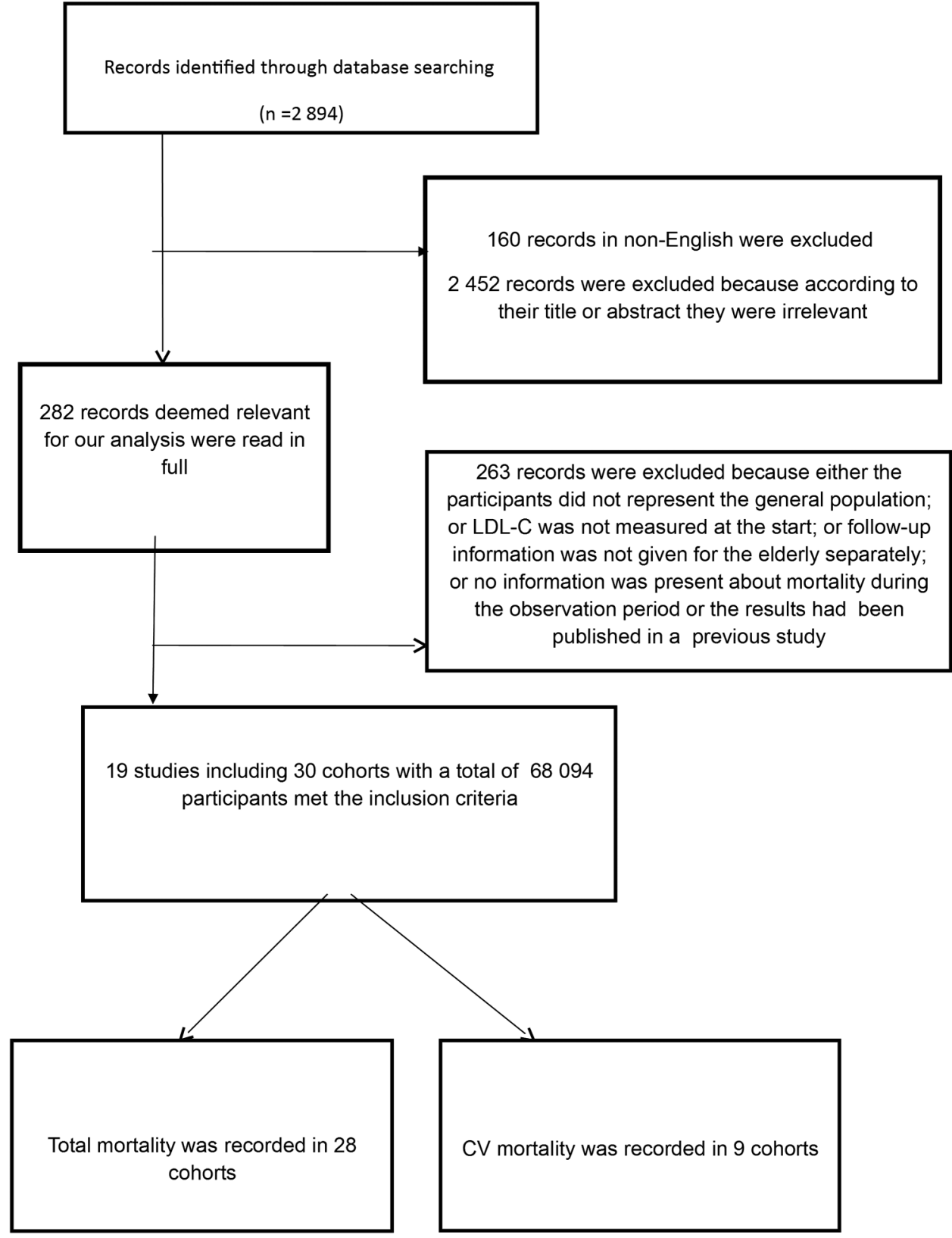

\section{Risk of bias across studies}

One explanation for the increased risk of mortality among people with low cholesterol is that serious diseases may lower cholesterol soon before death occurs. Evidence to support this hypothesis may be obtained from 10 of the studies in which no exclusions were made for individuals with terminal illnesses. However, in four of the studies, participants with a terminal illness or who had died during the first observation year were excluded. In one of those studies, ${ }^{8}$ LDL-C was not associated with all-cause mortality; in the three others, ${ }^{16} 2024$ which included more than $70 \%$ of the total number of participants in our review, LDL-C was inversely associated with all-cause mortality and with statistical significance. Thus, there is little support for the hypothesis that our analysis is biased by end of life changes in LDL-G levels.
It is also potentially relevant that all studies did not correct for the same risk factors, and some of them did not inform the reader about which risk factors they corrected for. However, taking all studies together, 50 different risk factors were corrected for in the Cox analyses (table 2).

It is worth considering that some of the participants with high LDL-C may have started statin treatment during the observation period. Such treatment may have increased the lifespan for the group with high LDL-C. However, any beneficial effects of statins on mortality would have been minimal because most statin trials have had little effect on CVD and all-cause mortality, with a maximum reduction of mortality of two percentage points. It is therefore relevant that the 4-year mortality among those with the highest LDL-C in the included cohorts was up to $36 \%$ lower than among those with the 
Table 1 Association between LDL-C and all-cause mortality and CVD mortality, respectively, in 19 studies including 30 cohorts with 68094 individuals from the general population above the age of 60 years

\begin{tabular}{|c|c|c|c|c|c|c|c|c|c|c|c|}
\hline \multirow[b]{2}{*}{ Authors } & \multirow[b]{2}{*}{ Race if indicated } & \multirow[b]{2}{*}{ Sex } & \multirow[b]{2}{*}{$\mathbf{N}$} & \multirow{2}{*}{$\begin{array}{l}\text { Age; } \\
\text { years }\end{array}$} & \multirow{2}{*}{$\begin{array}{l}\text { Obs. } \\
\text { Years }\end{array}$} & \multicolumn{4}{|c|}{$\begin{array}{l}\text { All-cause mortality } \\
\text { LDL-C tertiles or } \\
\text { quartiles (HRs) }\end{array}$} & \multirow[b]{2}{*}{ CV mortality } & \multirow[b]{2}{*}{ Exclusion criteria } \\
\hline & & & & & & $\mathbf{I}$ & II & III & IV & & \\
\hline \multirow{3}{*}{\multicolumn{2}{|c|}{$\begin{array}{l}\text { Zimetbaum et } a^{\beta} \\
\text { Kronmal et } a \beta^{\beta}\end{array}$}} & MF & 350 & $75-85$ & 6,3 & \multicolumn{4}{|c|}{ No association } & $\mathrm{NI}$ & Terminal illness, dementia \\
\hline & & MF & 747 & $66-75$ & 10 & \multicolumn{4}{|c|}{ No association } & $\mathrm{NI}$ & None \\
\hline & & & 176 & $>75$ & & \multicolumn{4}{|c|}{ No association } & $\mathrm{NI}$ & \\
\hline \multicolumn{2}{|c|}{ Räinä et $a l^{10}$} & MF & 347 & $\geq 65$ & 11 & \multicolumn{4}{|c|}{$\mathrm{NI}$} & No association & Living in an institution \\
\hline Fried et a & & MF & 5201 & $\geq 65$ & 4.8 & 1.0 & ? & $?$ & 0.66 (significant) & $\mathrm{NI}$ & Wheelchair user; cancer treatment \\
\hline \multirow{2}{*}{\multicolumn{2}{|c|}{ Chyou and Eaker ${ }^{11}$}} & M & 367 & $\geq 65$ & $8-10$ & \multirow{2}{*}{\multicolumn{4}{|c|}{$\begin{array}{l}\text { No association } \\
\text { No association }\end{array}$}} & $\mathrm{NI}$ & None \\
\hline & & $\mathrm{F}$ & 622 & & & & & & & & \\
\hline \multicolumn{2}{|c|}{ Weverling-Rijnsburger et $\mathrm{al}^{12}$} & MF & 599 & $\geq 85$ & 4 & 1.0 & 0.57 & \multicolumn{2}{|l|}{$\begin{array}{l}0.71 \\
p \text { for trend* }\end{array}$} & No association & None \\
\hline \multicolumn{2}{|c|}{ Schupf et $a l^{13}$} & MF & 2277 & $\geq 65$ & 3 & 1.0 & 0.79 & 0.63 & $\begin{array}{l}0.53 \\
p \text { for trend }\end{array}$ & $\mathrm{NI}$ & Dementia \\
\hline \multirow{2}{*}{\multicolumn{2}{|c|}{ Tikhonoff et al ${ }^{4}$}} & M & 1233 & $\geq 65$ & 11,1 & \multicolumn{4}{|c|}{$\begin{array}{l}\text { Mirror-J-formed association with the highest risk } \\
\text { in the lowest quartile }\end{array}$} & $\begin{array}{l}\text { Almost U-formed association } \\
\text { with the highest risk in the } \\
\text { lowest quartile* }\end{array}$ & Dementia \\
\hline & & $\mathrm{F}$ & 1887 & & & \multicolumn{4}{|c|}{ Inverse association* } & $\begin{array}{l}\text { Mirror-J-formed association } \\
\text { with the highest risk in the } \\
\text { lowest quartile* }\end{array}$ & \\
\hline \multirow{2}{*}{\multicolumn{2}{|c|}{$\begin{array}{l}\text { Störk et al }{ }^{15} \\
\text { Akerblom et } a l^{16}\end{array}$}} & M & 403 & $>70$ & 4 & \multicolumn{4}{|c|}{ No association } & No association & None \\
\hline & & \\
\hline Caucas & ans & MF & 705 & $\geq 65$ & 3.5 & 1.0 & 0.89 & 0.72 & $0.56^{*}$ & $\mathrm{NI}$ & Dementia, first year deaths \\
\hline African & Americans & MF & 797 & & & 1.0 & 0.79 & 0.58 & $0.53^{*}$ & & \\
\hline Hispan & & MF & 1054 & & & 1.0 & 0.79 & 0.79 & 0.71 & & \\
\hline Upmeier & $t a l^{17}$ & MF & 1032 & 70 & 12 & No a & ssociation & & & No association & None \\
\hline Nilsson $e$ & & $\mathrm{M}$ & 210 & 75 & 10 & No a & ssociation & & & $\mathrm{NI}$ & None \\
\hline & & $\mathrm{F}$ & 222 & & & No a & ssociation & & & & \\
\hline Werle et & & MF & 187 & $\geq 80$ & 8,7 & No a & ssociation & & & No association & None \\
\hline Bathum $e$ & $a^{20} \dagger$ & M & 13733 & $60-70$ & $1-9$ & 1.0 & $0.67^{\star \star *}$ & $0.49^{\star * \star}$ & $0.45^{\star \star \star}$ & $\mathrm{NI}$ & Terminal disease, CVD, diabetes, \\
\hline & & & 7493 & $\geq 70$ & & 1.0 & $0.71^{\star * *}$ & $0.60^{\star * \star}$ & $0.52^{\star \star \star}$ & & patients with a prescription of \\
\hline & & $\mathrm{F}$ & 14298 & $60-70$ & & 1.0 & $0.56^{\star \star *}$ & $0.45^{\star \star \star}$ & $0.47^{\star \star \star}$ & & statin during the last year before test date \\
\hline & & & 9142 & $\geq 70$ & & 1.0 & $0.66^{\star \star *}$ & $0.52^{\star \star \star}$ & $0.46^{\star \star \star}$ & & \\
\hline Linna et & & MF & 1260 & $\geq 64$ & 10 & Inve & se associ & on $^{\star \star}$ & & $\mathrm{NI}$ & None \\
\hline Jacobs e & & MF & 512 & $78-85$ & 8 & No a & ssociation & & & $\mathrm{NI}$ & None \\
\hline & & & 702 & 85-90 & 5 & No a & ssociation & & & & \\
\hline Takata et & & MF & 207 & 85 & 10 & $\begin{array}{l}\text { Sur } \\
2.9\end{array}$ & $\begin{array}{l}\text { vors } 3.2 \mathrm{n} \\
\mathrm{mol} / \mathrm{L}^{\star \star}\end{array}$ & nol/L; non-survil & vors: & No association & None \\
\hline Lv et $a P^{4}$ & & M & 266 & $\geq 80$ & 3 & 1.0 & 0.67 & 0.43 & $0.41^{*}$ & $\mathrm{NI}$ & First year deaths \\
\hline & & $\mathrm{F}$ & 596 & & & 1.0 & $0.69^{*}$ & $0.57^{* *}$ & $0.59^{*}$ & & \\
\hline & & MF & & & & 1.0 & $0.72^{*}$ & $0.59^{\star \star}$ & $0.60^{*}$ & & \\
\hline Blekkenh & rst et $a R^{25}$ & $\mathrm{~F}$ & 1469 & $\geq 70$ & 10 & $\mathrm{NI}$ & & & & No association & None \\
\hline
\end{tabular}


Table 2 Factors corrected for in the multifactorial analyses of each study

\begin{tabular}{|c|c|}
\hline Authors & Factors adjusted for \\
\hline Zimetbaum et al & Age, smoking, health self-rating, BMI, BP, diabetes, MI and IQ. \\
\hline Kronmal et al & Age, sex, BP, BMI, BMl squared, smoking. \\
\hline Räihä et al & Age, sex, smoking, alcohol use, BMI, CHD, BP and diabetes. \\
\hline Fried et al & $\begin{array}{l}\text { Race, height, hip and waist circumference, BMI, smoking, diastolic BP, antihypertensive and } \\
\text { lipid-lowering treatment, TC, HDL-C, TG, diabetes, fasting insulin, factor VII and VIII, serum } \\
\text { potassium and uric acid, asthma, emphysema, angina, MI, stroke, claudication, arthritis, renal } \\
\text { disease, cancer, hearing and visual impairment, FEV, mitral stenosis and regurgitation, carotid } \\
\text { stenosis }\end{array}$ \\
\hline Chyou and Eaker & Age, sex, CHD, stroke, cancer, diabetes, BP, BMI, smoking, alcohol consumption \\
\hline $\begin{array}{l}\text { Weverling-Rijnsburger } \\
\text { et al }\end{array}$ & Comorbidities, BMI, use of $\beta$-blocking agents, thyroid dysfunction \\
\hline Schupf et al & $\begin{array}{l}\text { Age, sex, ethnic group, BMI, level of education, APOE genotype, diabetes, heart disease, stroke, } \\
\text { cancer, smoking }\end{array}$ \\
\hline Tikhonoff et al & $\begin{array}{l}\text { Age, BP, pulse rate, BMI, CV events, smoking, alcohol intake, diabetes, serum creatinine and uric } \\
\text { acid. }\end{array}$ \\
\hline Störk et al & Cox regression analysis. No details \\
\hline Akerblom et al & $\begin{array}{l}\text { Age, sex, education, BMI, APOE genotype, heart disease, BP, diabetes, stroke, dementia, } \\
\text { smoking. }\end{array}$ \\
\hline Upmeier et al & Gender, BMI, smoking, angina pectoris, stroke, diabetes, hypertension, cancer \\
\hline Nilsson et al & BMI, smoking, non-HDL-C, TG, BP, diabetes, previous MI \\
\hline Werle et al & $\begin{array}{l}\text { Factors that showed a trend for association in the univariate analyses, well-known risk factors for } \\
\text { total mortality or cardiovascular mortality. }\end{array}$ \\
\hline Bathum et al & Cox regression analysis. No details \\
\hline Linna et al & Age, sex, BMI, smoking, BP, diabetes \\
\hline Jacobs et al & Statin treatment, sex, CHD, BP, neoplasm, self-rated health, smoking, albumin, BMI, triglycerides. \\
\hline Takata et al & Sex, smoking, alcohol intake, stroke, heart disease, serum albumin, BMI, systolic BP \\
\hline Lv et al 2015 & $\begin{array}{l}\text { Age, sex, marital status, smoking, alcohol drinking, tea drinking, central obesity, cognitive } \\
\text { impairment, daily activity, blindness, anaemia, BT, diabetes, CKD, HDL-C }\end{array}$ \\
\hline Blekkenhorst et al & $\begin{array}{l}\text { Age, BMI, physical activity, renal function, smoking, diabetes, CVD, low-dose aspirin, } \\
\text { antihypertensive and statin medication, energy intake, SFA }\end{array}$ \\
\hline
\end{tabular}

lowest LDL-C. Furthermore, in the largest study ${ }^{20}$ that included about two-thirds of the total number of participants in our study, the risk was lower among those with the highest LDL-C than among those on statin treatment.

It is also possible that those with the highest LDL-C were put on a different diet than those with low LDL-C. However, this potential bias in mortality outcomes could have gone in both directions. Some of the individuals with high LDL-C may have followed the official dietary guidelines and exchanged saturated fat with vegetable oils rich in linoleic acid. In a recent study, the authors reported that among participants who were older than 65 at baseline, a $30 \mathrm{mg} / \mathrm{dL}$ decrease in serum cholesterol was associated with a higher risk of death (HR $1.35,95 \%$ CI 1.18 to 1.54$).{ }^{26}$ If applied to the general population, this finding suggests that the conventional dietary treatment for high cholesterol with vegetable oil replacing saturated fat may actually increase mortality in those individuals with high LDL-C. Thus, the lack of an association between LDL-C and mortality may have been even stronger than reported since the dietary intervention may have been counterproductive.

Finally, it is potentially relevant that we limited our literature search to PubMed. In preliminary searches with PubMed, OVID and EMBASE, we identified 17 relevant studies in PubMed, but only 2 in OVID and EMBASE, and these 2 studies were found in PubMed as well. Therefore, it is highly unlikely that there are studies with findings with divergent results from those we have reported here, as all of them reported either no association or an inverse association between LDL-C and mortality.

\section{DISCUSSION}

Assessments of the association between serum cholesterol and mortality have been studied for decades, and extensive research has shown a weak association between total cholesterol and mortality in the elderly; several studies have even shown an inverse association. It is therefore surprising that there is an absence of a review of the literature on mortality and levels of LDL-C, which is routinely 
referred to as a causal agent in producing $\mathrm{CVD}^{4}$ and is a target of pharmacological treatment of CVD.

Our literature review has revealed either a lack of an association or an inverse association between LDL-C and mortality among people older than 60 years. In almost $80 \%$ of the total number of individuals, LDL-C was inversely associated with all-cause mortality and with statistical significance.

These findings provide a paradoxical contradiction to the cholesterol hypothesis. As atherosclerosis starts mainly in middle-aged people and becomes more pronounced with increasing age, the cholesterol hypothesis would predict that there should be a cumulative atherosclerotic burden, which would be expressed as greater CVD and all-cause mortality, in elderly people with high LDL-C levels.

Our results raise several relevant questions for future research. Why is high TC a risk factor for CVD in the young and middle-aged, but not in elderly people? Why does a subset of elderly people with high LDL-C live longer than people with low LDL-C? If high LDL-C is potentially beneficial for the elderly, then why does cholesterol-lowering treatment lower the risk of cardiovascular mortality? In the following we have tried to address some of these questions.

\section{Inverse causation}

A common argument to explain why low lipid values are associated with an increased mortality is inverse causation, meaning that serious diseases cause low cholesterol. However, this is not a likely explanation, because in five of the studies in table 1 terminal disease and mortality during the first years of observation were excluded. In spite of that, three of them showed that the highest mortality was seen among those with the lowest initial LDL-C with statistical significance. ${ }^{18} 2024$

\section{Is high LDL-C beneficial?}

One hypothesis to address the inverse association between LDL-C and mortality is that low LDL-C increases susceptibility to fatal diseases. Support for this hypothesis is provided by animal and laboratory experiments from more than a dozen research groups which have shown that LDL binds to and inactivates a broad range of microorganisms and their toxic products. ${ }^{27}$ Diseases caused or aggravated by microorganisms may therefore occur more often in people with low cholesterol, as observed in many studies. ${ }^{28}$ In a meta-analysis of 19 cohort studies, for instance, performed by the National Heart, Lung and Blood Institute and including 68406 deaths, TC was inversely associated with mortality from respiratory and gastrointestinal diseases, most of which are of an infectious origin. ${ }^{29}$ It is unlikely that these diseases caused the low TC, because the associations remained after the exclusion of deaths occurring during the first 5 years. In a study by Iribarren et al, more than 100000 healthy individuals were followed for
15 years. At follow-up, those whose initial cholesterol level was lowest at the start had been hospitalised significantly more often because of an infectious disease that occurred later during the 15-year follow-up period. ${ }^{30}$ This study provides strong evidence that low cholesterol, recorded at a time when these people were healthy, could not have been caused by a disease they had not yet encountered.

Another explanation for an inverse association between LDL-C and mortality is that high cholesterol, and therefore high LDL-C, may protect against cancer. The reason may be that many cancer types are caused by viruses. ${ }^{31}$ Nine cohort studies including more than 140000 individuals followed for 10-30 years have found an inverse association between cancer and TC measured at the start of the study, even after excluding deaths that occurred during the first 4 years. ${ }^{32}$ Furthermore, cholesterollowering experiments on rodents have resulted in cancer, ${ }^{33}$ and in several case-control studies of patients with cancer and controls matched for age and sex, significantly more patients with cancer have been on cholesterol-lowering treatment. ${ }^{32}$ In agreement with these findings, cancer mortality is significantly lower in individuals with familial hypercholesterolaemia. ${ }^{34}$

That high LDL-C may be protective is in accordance with the finding that LDL-C is lower than normal in patients with acute myocardial infarction. This has been documented repeatedly without a reasonable explanation. ${ }^{35-37}$ In one of the studies, ${ }^{37}$ the authors concluded that LDL-C evidently should be lowered even more, but at a follow-up 3 years later mortality was twice as high among those whose LDL-C had been lowered the most compared with those whose cholesterol was unchanged or lowered only a little. If high LDL-C were the cause, the effect should have been the opposite.

\section{CONCLUSIONS}

Our review provides the first comprehensive analysis of the literature about the association between LDL-C and mortality in the elderly. Since the main goal of prevention of disease is prolongation of life, all-cause mortality is the most important outcome, and is also the most easily defined outcome and least subject to bias. The cholesterol hypothesis predicts that LDL-C will be associated with increased all-cause and CV mortality. Our review has shown either a lack of an association or an inverse association between LDL-C and both all-cause and CV mortality. The cholesterol hypothesis seems to be in conflict with most of Bradford Hill's criteria for causation, because of its lack of consistency, biological gradient and coherence. Our review provides the basis for more research about the cause of atherosclerosis and CVD and also for a re-evaluation of the guidelines for cardiovascular prevention, in particular because the benefits from statin treatment have been exaggerated. ${ }^{38-40}$ 
Author affiliations

${ }^{1}$ Magle Stora Kyrkogata 9, 22350 Lund, Sweden

${ }^{2}$ Department of Psychology, Department of Molecular Pharmacology and Physiology, Center for Preclinical and Clinical Research on PTSD, University of South Florida, Tampa, Florida, USA

${ }^{3} \mathrm{NPO}$ Japan Institute of Pharmacovigilance, Osaka, Japan

${ }^{4}$ Department of Internal Medicine, Toyama Jonan Onsen Daini Hospital, University of Toyama, Toyama City, Japan

${ }^{5}$ Strömstad Academy, Strömstad, Sweden

${ }^{6}$ Western Vascular Institute, University Hospital Galway \& Galway Clinic, National University of Ireland \& Royal college of Surgeons of Ireland affiliated Hospital, Galway, Ireland

${ }^{7}$ East Cheshire Trust, Macclesfield District General Hospital, Macclesfield, Cheshire, England

${ }^{8}$ Solo Practice in Cardiology, Tyler, Texas 75701, USA

${ }^{9}$ Department of cardiology, Frimley Park Hospital, Portsmouth road, Surrey GU16 7UJ, UK

${ }^{10}$ Medical Service, Comando Brigata Alpina "Julia"/Multinational Land Force, Udine, Italy

${ }^{11}$ Pathology and Laboratory Medicine Service, VA Boston Healthcare System, West Roxbury; Harvard Medical School, Boston, Massachusetts

${ }^{12}$ Tokai University, Daikancho, Hiratsuka, Kanagawa, Japan 254-0807

${ }^{13}$ Nagoya City University and Institute for Consumer Science and Human Life, Kinjo Gakuin University, Nagoya, Japan

${ }^{14} \mathrm{New}$ York Medical College; The American Institute of Stress

${ }^{15}$ Sahlgren's Academy, University of Gothenburg, Sweden, and Colombia

University, NY, USA

${ }^{16}$ Slottsstadens Läkarhus, Malmö, Gothenburg, Sweden

Acknowledgements The study has been supported by a grant from Western Vascular Institute.

Contributors UR and RS performed the paper search independently. UR wrote the first draft of the manuscript. All authors have read the papers and made improvements of the content and the wording. The relevant data from each study have been examined by at least three of the authors.

Competing interests TH has received speaker fees from Nissui Pharmaceutical and Nippon Suisan Kaisha. KSM has a US patent for a homocysteine-lowering protocol. RH, HO, RS and UR have written books with criticism of the cholesterol hypothesis.

Provenance and peer review Not commissioned; externally peer reviewed.

Open Access This is an Open Access article distributed in accordance with the Creative Commons Attribution Non Commercial (CC BY-NC 4.0) license, which permits others to distribute, remix, adapt, build upon this work noncommercially, and license their derivative works on different terms, provided the original work is properly cited and the use is non-commercial. See: http:// creativecommons.org/licenses/by-nc/4.0/

\section{REFERENCES}

1. Ravnskov U. Is atherosclerosis caused by high cholesterol? QJM 2002;95:397-403.

2. Hamazaki T, Okuyama $H$, Ogushi $Y$, et al. Towards a paradigm shift in cholesterol treatment-a re-examination of the cholesterol issue in Japan. Ann Nutr Metab 2015;66(Suppl 4):1-116.

3. Prospective Studies CollaborationLewington S, Whitlock G, Clarke $\mathrm{R}$, et al. Blood cholesterol and vascular mortality by age, sex, and blood pressure: a meta-analysis of individual data from 61 prospective studies with 55,000 vascular deaths. Lancet 2007;370:1829-39.

4. Goldstein JL, Brown MS. A century of cholesterol and coronaries: from plaques to genes to statins. Cell 2015;161:161-72.

5. Stang A. Critical evaluation of the Newcastle-Ottawa scale for the assessment of the quality of nonrandomized studies in meta-analyses. Eur J Epidemiol 2010;25:603-5.

6. Psaty BM, Anderson M, Kronmal RA, et al. The association between lipid levels and the risks of incident myocardial infarction, stroke, and total mortality: the Cardiovascular Health Study. J Am Geriatr Soc 2004;52:1639-47.

7. Fried LP, Kronmal RA, Newman AB, et al. Risk factors for 5-year mortality in older adults: the Cardiovascular Health Study. JAMA 1998;279:585-92.
8. Zimetbaum P, Frishman WH, Ooi WL, et al. Plasma lipids and lipoproteins and the incidence of cardiovascular disease in the very elderly: the Bronx Aging Study. Arterioscler Thromb 1992;12:416-23.

9. Kronmal RA, Cain KC, Ye Z, et al. Total serum cholesterol levels and mortality risk as a function of age. A report based on the Framingham data. Arch Intern Med 1993;153:1065-73.

10. Räihä I, Marniemi J, Puukka P, et al. Effect of serum lipids, lipoproteins, and apolipoproteins on vascular and nonvascular mortality in the elderly. Arterioscler Thromb Vasc Biol 1997;17:1224-32.

11. Chyou PH, Eaker ED. Serum cholesterol concentrations and all-cause mortality in older people. Age Ageing 2000;29:69-74.

12. Weverling-Rijnsburger AW, Jonkers IJ, van Exel E, et al. High-density vs low-density lipoprotein cholesterol as the risk factor for coronary artery disease and stroke in old age. Arch Intern Med 2003;163:1549-54.

13. Schupf N, Costa R, Luchsinger J, et al. Relationship between plasma lipids and all-cause mortality in nondemented elderly. J Am Geriatr Soc 2005;53:219-26.

14. Tikhonoff V, Casiglia E, Mazza A, et al. Low-density lipoprotein cholesterol and mortality in older people. $J$ Amer Geriatr Soc 2005;53:2159-64.

15. Störk S, Feelders RA, van den Beld AW, et al. Prediction of mortality risk in the elderly. Am J Med 2006;119:519-25.

16. Akerblom JL, Costa R, Luchsinger JA, et al. Relation of plasma lipids to all-cause mortality in Caucasian, African-American and Hispanic elders. Age Ageing 2008;37:207-13.

17. Upmeier E, Lavonius S, Lehtonen A, et al. Serum lipids and their association with mortality in the elderly: a prospective cohort study. Aging Clin Exp Res 2009;21:424-30.

18. Nilsson G, Ohrvik J, Lönnberg I, et al. Ten-year survival in 75-year-old men and women: predictive ability of total cholesterol, HDL-C, and LDL-C. Curr Gerontol Geriatr Res 2009:158425. doi:10.1155/2009/158425

19. Werle MH, Moriguchi E, Fuchs SC, et al. Risk factors for cardiovascular disease in the very elderly: results of a cohort study in a city in southern Brazil. Eur J Cardiovasc Prev Rehabil 2011;18:369-77.

20. Bathum L, Depont Christensen R, Engers Pedersen L, et al. Association of lipoprotein levels with mortality in subjects aged 50 +without previous diabetes or cardiovascular disease: a population-based register study. Scand J Prim Health Care 2013;31:172-80.

21. Linna M, Ahotupa M, Löppönen MK, et al. Circulating oxidised LDL lipids, when proportioned to HDL-C emerged as a risk factor of all-cause mortality in a population-based survival study. Age Ageing 2013:42:110-13.

22. Jacobs JM, Cohen A, Ein-Mor E, et al. Cholesterol, statins, and longevity from age 70 to 90 years. J Am Med Dir Assoc 2013;14:883-8.

23. Takata $Y$, Ansai T, Soh I, et al. Serum total cholesterol concentration and 10-year mortality in an 85-year-old population. Clin Interv Aging 2014:9:293-300.

24. Lv YB, Yin ZX, Chei CL, et al. Low-density lipoprotein cholesterol was inversely associated with 3-year all-cause mortality among Chinese oldest old: data from the Chinese Longitudinal Healthy Longevity Survey. Atherosclerosis 2015;239: $137-42$.

25. Blekkenhorst LC, Prince RL, Hodgson JM, et al. Dietary saturated fat intake and atherosclerotic vascular disease mortality in elderly women: a prospective cohort study. Am J Clin Nutr 2015;101:1263-8.

26. Ramsden CE, Zamora D, Majchrzak-Hong S, et al. Re-evaluation of the traditional diet-heart hypothesis: analysis of recovered data from Minnesota Coronary Experiment (1968-73). BMJ 2016;353: i1246.

27. Ravnskov $U$, McCully KS. Vulnerable plaque formation from obstruction of vasa vasorum by homocysteinylated and oxidized lipoprotein aggregates complexed with microbial remnants and LDL autoantibodies. Ann Clin Lab Sci 2009;39:3-16.

28. Ravnskov U. High cholesterol may protect against infections and atherosclerosis. QJM 2003;96:927-34.

29. Jacobs $\mathrm{D}$, Blackburn $\mathrm{H}$, Higgins $\mathrm{M}$, et al. Report of the conference on low blood cholesterol: mortality associations. Circulation 1992;86:1046-60.

30. Iribarren C, Jacobs DR Jr, Sidney S, et al. Cohort study of serum total cholesterol and in-hospital incidence of infectious diseases. Epidemiol Infect 1998;121:335-47.

31. Read SA, Douglas MW. Virus induced inflammation and cancer development. Cancer Lett 2014;345:174-81. 
32. Ravnskov U, McCully KS, Rosch PJ. The statin-low cholesterol-cancer conundrum. QJM 2012;105:383-8.

33. Newman TB, Hulley SB. Carcinogenicity of lipid-lowering drugs. JAMA 1996;275:55-60.

34. Neil HA, Hawkins MM, Durrington PN, et al. Non-coronary heart disease mortality and risk of fatal cancer in patients with treated heterozygous familial hypercholesterolaemia: a prospective registry study. Atherosclerosis 2005;179:293-7.

35. Reddy VS, Bui QT, Jacobs JR, et al. Relationship between serum low-density lipoprotein cholesterol and In-hospital mortality following acute myocardial infarction (The lipid paradox). Am J Cardiol 2015;115:557-62.

36. Sachdeva A, Cannon CP, Deedwania PC, et al. Lipid levels in patients hospitalized with coronary artery disease: an analysis of 136,905 hospitalizations in get with the guidelines. Am Heart J 2009;157:111-17.
37. Al-Mallah $\mathrm{MH}$, Hatahet $\mathrm{H}$, Cavalcante $\mathrm{JL}$, et al. Low admission LDL-cholesterol is associated with increased 3-year all-cause mortality in patients with non ST segment elevation myocardial infarction. Cardiol J 2009;16:227-33.

38. Diamond DM, Ravnskov U. How statistical deception created the appearance that statins are safe and effective in primary and secondary prevention of cardiovascular disease. Expert Rev Clin Pharmacol 2015;8:201-10.

39. Kristensen ML, Christensen PM, Hallas J. The effect of statins on average survival in randomised trials, an analysis of end point postponement. BMJ Open 2015;5:e007118.

40. de Lorgeril M, Rabaeus M. Beyond confusion and controversy, Can we evaluate the real efficacy and safety of cholesterol-lowering with statins? J Controversies Biomed Res 2015;1:67-92. 